\title{
Histopathological predictive factors in Ewing's sarcoma of bone and clinicopathological correlations
} A retrospective study of 261 cases

A. Llombart-Bosch, G. Contesso, M. Henry-Amar, M.J. Lacombe, O. Oberlin, J. Dubousset, J. Rouëssé, and D. Sarrazin

Virchows Arch [Pathol Anat] 409:627-640

Due to an unfortunate error Figure $1 \mathrm{~b}$ was omitted and Figure 1c appeared twice. The correct Figure $1 \mathrm{~b}$ is shown below:

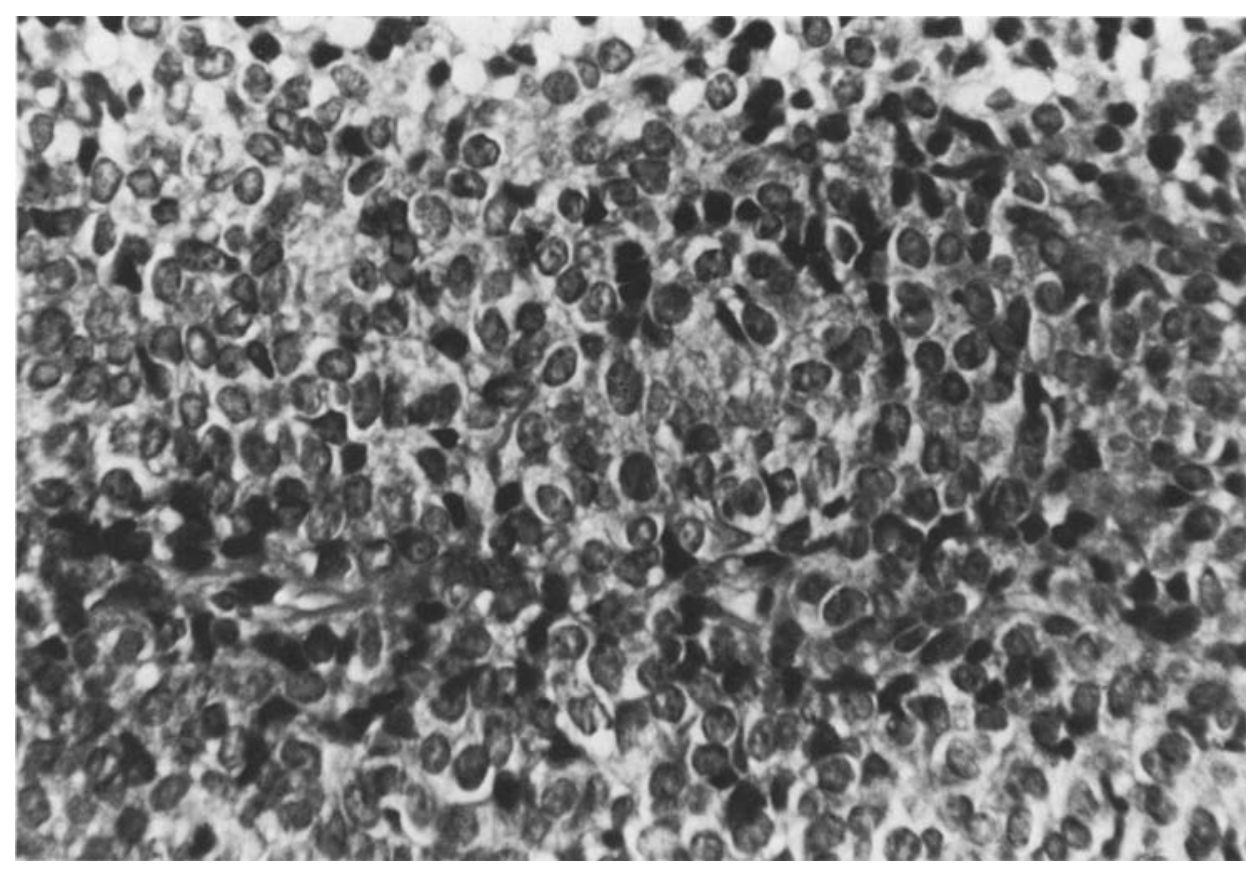

